ARTICLE

Received 20 Mar 2015 | Accepted 25 Jul 2015 | Published 9 Sep 2015

DOI: $10.1038 /$ ncomms9178

OPEN

\title{
The interactions between a small molecule and G-quadruplexes are visualized by fluorescence lifetime imaging microscopy
}

\author{
Arun Shivalingam¹, M. Angeles Izquierdo ${ }^{1}$ Alix Le Marois², Aurimas Vyšniauskas ${ }^{1}, K^{2}$ laus Suhling², \\ Marina K. Kuimova ${ }^{1} \&$ Ramon Vilar ${ }^{1}$
}

Guanine-rich oligonucleotides can fold into quadruple-stranded helical structures known as G-quadruplexes. Mounting experimental evidence has gathered suggesting that these non-canonical nucleic acid structures form in vivo and play essential biological roles. However, to date, there are no small-molecule optical probes to image G-quadruplexes in live cells. Herein, we report the design and development of a small fluorescent molecule, which can be used as an optical probe for $\mathrm{G}$-quadruplexes. We demonstrate that the fluorescence lifetime of this new probe changes considerably upon interaction with different nucleic acid topologies. Specifically, longer fluorescence lifetimes are observed in vitro for G-quadruplexes than for double- and single-stranded nucleic acids. Cellular studies confirm that this molecule is cell permeable, has low cytotoxicity and localizes primarily in the cell nucleus. Furthermore, using fluorescence lifetime imaging microscopy, live-cell imaging suggests that the probe can be used to study the interaction of small molecules with G-quadruplexes in vivo.

\footnotetext{
${ }^{1}$ Department of Chemistry, Imperial College London, South Kensington, London SW7 2AZ, UK. 2 Department of Physics, King's College London, Strand, London WC2R 2LS, UK. Correspondence and requests for materials should be addressed to M.K.K. (email: m.kuimova@imperial.ac.uk)

or to R.V. (email: r.vilar@imperial.ac.uk).
} 
T he dynamic nature of DNA enables a range of non-canonical structures to potentially form in vivo. G-quadruplexes, in particular, have received increasing attention having been implicated in biologically important roles such as genomic instability, telomerase dysfunction and the regulation of gene expression ${ }^{1-3}$. Yet there still remains considerable debate as to whether these structures form in vivo; given that $\mathrm{G}$-quadruplexes arise from non-covalent interactions, isolating them in their native form from live cells is a very challenging task. As a result, many studies have focused on fixed cells where the structural dynamics of nucleic acids can be more readily controlled. Encouragingly, in this context, G-quadruplexes have been visualized using antibodies ${ }^{4-6}$. However, questions remain as to whether these observations are the result of artefacts from chromatin fixation ${ }^{7,8}$, or if the high affinity of the antibodies induce G-quadruplex formation. Moreover, dynamic relationships between G-quadruplex formation and its cellular consequences are precluded from these studies. Of these points, cell-permeable small-molecule optical probes would provide an ideal means of monitoring these structures in live cells and in real-time overcoming the limitation of fixed cell artefacts ${ }^{9,10}$. Furthermore, such probes would provide invaluable insight into the criteria required for 'drugability' of G-quadruplexes. While a number of optical probes for G-quadruplexes have been reported over the past few years, to date none of these has been convincingly used to image them in live cells ${ }^{11-14}$.

High levels of selectivity for G-quadruplexes over duplex DNA have been achieved in vitro by designing molecules that have the appropriate shape and size to fit on top of the G-tetrad ${ }^{15}$. Typical ligand features include large aromatic surfaces for end-on $\pi-\pi$ stacking with G-tetrads, a central positive charge to favourably polarize the aromatic system and steric bulk that prevents intercalation into double-stranded (ds) DNA. However, establishing the extent to which these features translate to target engagement in live cells is not a trivial process ${ }^{16,17}$. Hence, the development of probes that can incorporate these features while possessing photophysical properties that can be monitored in vivo could provide crucial information regarding quadruplex-ligand interactions.

Highly stable planarized triarylmethyl carbocations named trianguleniums provide an ideal platform for such a probe (Fig. 1). These compounds have suitable structural features to interact with nucleic acids, they can be functionalized ${ }^{18-21}$ and, more importantly, they have intrinsic fluorescence that arises from the aromatic core ${ }^{22,23}$ Yet, surprisingly, no DNA binding studies have been reported for variants of the first reported triangulenium, namely TOTA $^{24,25}$. This is probably due to the limited number of non-alkyl modifications reported to date together with the modest affinity of TOTA for DNA $\left(K_{\mathrm{a}} \sim 10^{4}\right)$. Furthermore, as is typical of small-molecule optical probes, nucleic acids quench the emission of TOTA. Nonetheless, it was envisaged that, first, subtle alteration of the electronic and in turn redox properties of the aromatic core would enable a fluorescence 'turn-on' system to be obtained; and that, second, the affinity of triangulenium core for nucleic acids (in particular G-quadruplexes) could be significantly enhanced by the addition of appropriately placed substituents to the core.

Herein we present the synthesis and photophysical characterization of new triangulenium derivatives ADOTA-M and DAOTA-M2 (Fig. 1). We demonstrate a 'turn-on' fluorescence enhancement for DAOTA-M2 in the presence of nucleic acids as well as significant dependence of its fluorescence lifetime on nucleic acid topology using a wide range of in vitro DNA and RNA models. After showing that it is possible to detect G-quadruplexes even in the presence of other competing nucleic acid topologies, we also report fluorescence lifetime imaging microscopy (FLIM) studies of this probe in live cells. Our data show that this probe has a great potential to study the interaction between small molecules and G-quadruplexes in live cells.

\section{Results}

Synthesis of optical probes. The new compounds ADOTA-M and DAOTA-M2 were prepared following procedures previously reported for analogous mono- and bis-substituted trianguleniums (Fig. 1) ${ }^{20}$. Both compounds show the expected resonances in the ${ }^{1} \mathrm{H}$ nuclear magnetic resonance spectra where the integration between the core aromatic protons and the aliphatic substituents are consistent with mono- and bis-substituted trianguleniums for ADOTA-M and DAOTA-M2, respectively. The formulations were confirmed by mass spectrometry and elemental analyses (Supplementary Methods).

Photophysical properties of TOTA, ADOTA-M and DAOTA-M2. Trianguleniums have interesting photophysical properties, which can be used for sensing and imaging. Yet the incorporation of tertiary amines covalently linked to the fluorophore can significantly alter these properties ${ }^{26}$. Thus, before studying their
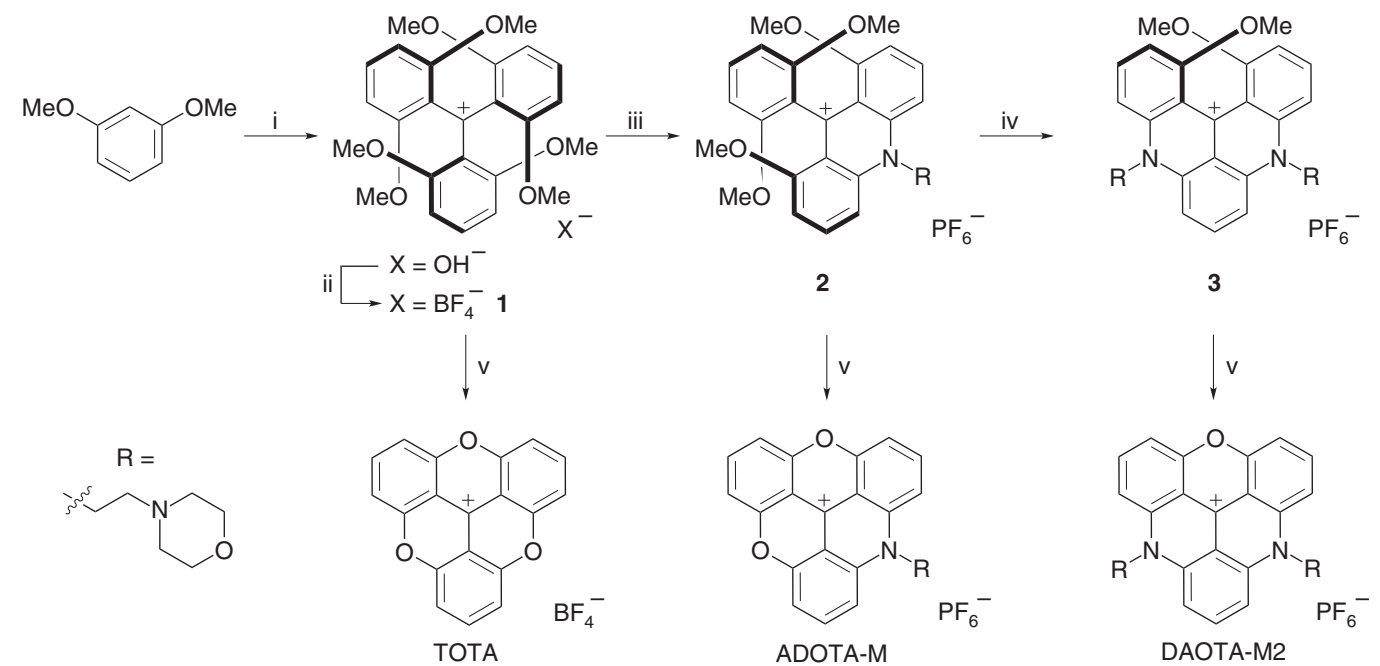

Figure 1 | Synthetic route to trianguleniums. (i) ${ }^{n} \mathrm{BuLi}, \mathrm{TEMED}, \mathrm{Et}_{2} \mathrm{O}, \mathrm{O}^{\circ} \mathrm{C}$ to rt then (EtO) ${ }_{2} \mathrm{CO}, 18 \mathrm{~h}$; (ii) $\mathrm{HBF}_{4} \cdot \mathrm{Et}_{2} \mathrm{O}, \mathrm{Et}_{2} \mathrm{O}, \mathrm{rt} 5 \mathrm{~min}$; (iii) $\mathrm{RNH}_{2}, \mathrm{NMP}$ room temperature, $2 \mathrm{~h}$ then $\mathrm{NH}_{4} \mathrm{PF}_{6}$ (aq); (iv) $\mathrm{RNH}_{2}, \mathrm{NMP}, 110{ }^{\circ} \mathrm{C}, 2 \mathrm{~h}$ then $\mathrm{NH}_{4} \mathrm{PF}_{6(\mathrm{aq})} ;(\mathrm{v}) \mathrm{Py} \cdot \mathrm{HCl}, 200^{\circ} \mathrm{C}, 1 \mathrm{~h}$. 

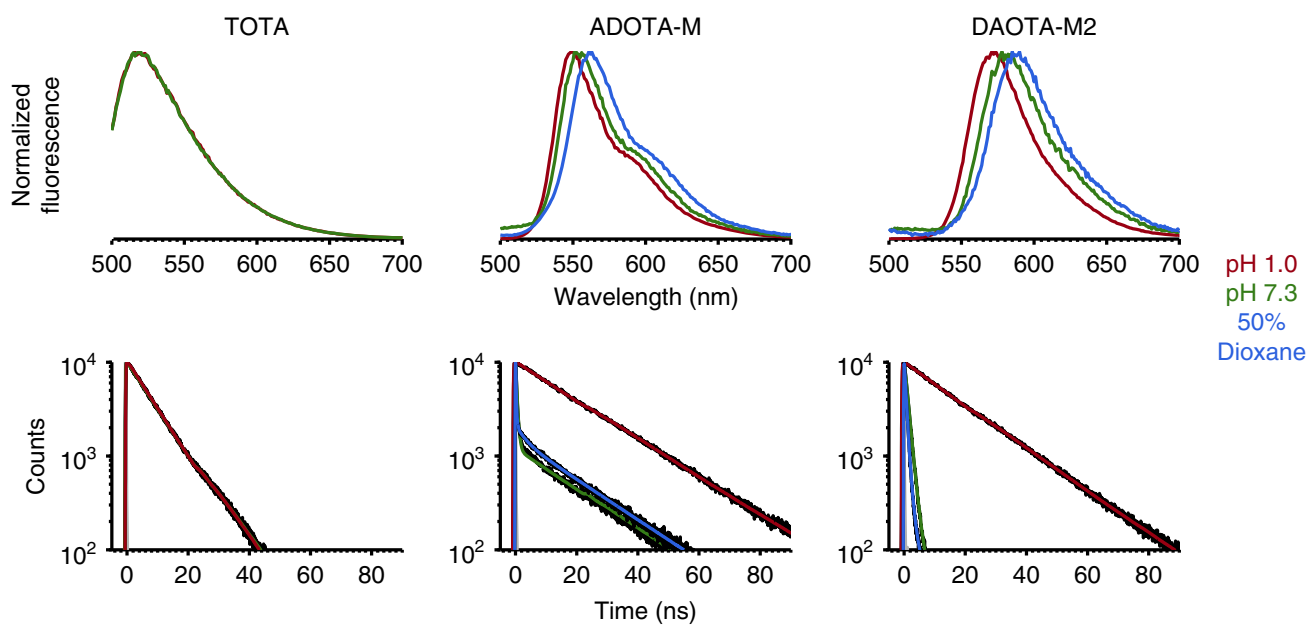

Figure 2 | The effect of the local aqueous environment on the fluorescence of TOTA, ADOTA-M and DAOTA-M2. pH 1.0 (red) and 7.3 (green) measurements were recorded in $0.1 \mathrm{M} \mathrm{HCl}$ and $10 \mathrm{mM}$ lithium cacodylate buffer containing $100 \mathrm{mM} \mathrm{KCl}(\mathrm{pH} 7.3$ ). Measurements in $50 \%$ 1,4-dioxane (blue) were recorded at $\mathrm{pH}$ 7.3. For TCSPC traces, raw data and the IRF are coloured black and grey, respectively.

Table 1 | Photophysical properties of TOTA, ADOTA-M and DAOTA-M2 in different local aqueous environments.

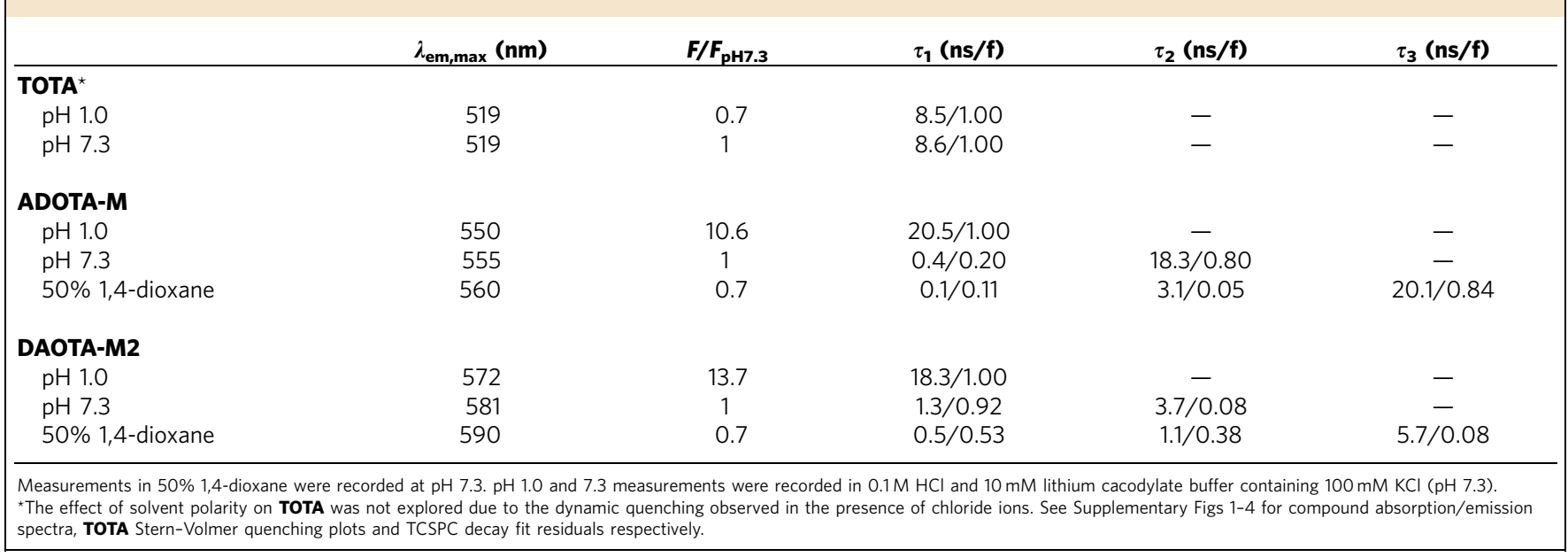

interaction with nucleic acids, the response of the compounds to changes in the local aqueous environment (for example, oxygen concentration, polarity, viscosity and $\mathrm{pH}$ ) was investigated and the main changes observed are summarized in Fig. 2 and Table 1. As will be discussed later, this information provides important clues regarding the photophysical changes the probes undergo upon their interaction with nucleic acids.

Under physiological conditions $(10 \mathrm{mM}$ lithium cacodylate ( $\mathrm{pH} \mathrm{7.3)} \mathrm{and} 100 \mathrm{mM} \mathrm{KCl}$ ), the quantum yields of ADOTA-M and DAOTA-M2 are 0.042 and 0.032 , respectively. Neither variation of ionic strength $(0-220 \mathrm{mM} \mathrm{KCl})$ nor deoxygenation of the solutions, have any significant effect upon fluorescence. However, simultaneously decreasing solvent polarity and increasing viscosity by the addition of 1,4-dioxane results in $\sim 0.3$-fold reduction of fluorescence and a red shift in emission maxima.

The time correlated-single photon counting (TCSPC) fluorescence lifetime data show that bi-exponential decays (or tri-exponential in the case of 1,4-dioxane/water mixtures) are necessary to adequately describe the above systems. This suggests that at least two emitting species are present in solution for ADOTA-M and DAOTA-M2. An excited state equilibrium between the carbocation and carbinol forms of the compounds can be excluded due to the mono-exponential decay of TOTA, which has the lowest $\mathrm{p} K_{\mathrm{R}}^{+}$(a measure of carbocation stability) for triangulenium compounds reported to date ${ }^{27}$. As a consequence, protonation of the morpholino group(s) was explored.

Steady-state emission $\mathrm{pH}$ titrations reveal the excited $\mathrm{p} K_{\mathrm{a}}{ }^{*}$ to be $4.68 \pm 0.10$ and $4.54 \pm 0.13$ for ADOTA-M and DAOTA-M2 ( \pm values $=$ s.d., $n=3$; Supplementary Fig. 5 ), respectively, while TOTA, which has no amines, shows no such $\mathrm{pH}$ dependence. Comparison of the spectra at $\mathrm{pH} 7.3$ and 1.0 shows that protonation of the amines results in a substantial enhancement of fluorescence ( $\sim 10-15$-fold) and long-lived mono-exponential fluorescence decays (Fig. 2 and Table 1). Furthermore, at pH 7.3, the fluorescence intensity decay of DAOTA-M2 is not concentration dependent $(0.2-50 \mu \mathrm{M}$; Supplementary Fig. 6). Therefore, as is well established in the literature ${ }^{28}$, this indicates that the shorter fluorescence lifetime component at $\mathrm{pH} 7.3$ is due to intramolecular photo-induced electron transfer (PET) interaction between a donor amine and excited state acceptor fluorophore.

It is also interesting to note that at pH 7.3, ADOTA-M retains a substantial proportion of the long-lived fluorescence component, whereas for DAOTA-M2 this value is significantly lower. This suggests that in addition to protonation, conformational changes at the nanosecond time scale may be of importance. In the case of DAOTA-M2, the number of morpholino groups incorporated in the molecule most likely enhances the probability of PET. 
Interactions of trianguleniums with DNA. Having established the key photophysical properties of these molecules, the effect of different DNA topologies on the steady-state emission of the three trianguleniums under study was investigated. These investigations showed that irrespective of topology, DNA strongly quenches the emission of TOTA (as previously reported ${ }^{24}$ ) and ADOTA-M. Interestingly, this was not the case with DAOTA-M2, which displayed fluorescence enhancement on the addition of DNA. This enhancement is unlikely to be associated with changes in protonation since a red shift $(1-4 \mathrm{~nm})$ in emission was observed on binding to DNA rather than the blue shift associated to protonation (Fig. 2 and Table 1). It is also unlikely to be associated with the local environment inside DNA-which has low polarity-as the photophysics in low polarity 1,4-dioxane/water mixtures (see above) suggests that fluorescence should be quenched. As a consequence of this unexpected DNA binding-dependent behaviour, the potential of the compound to be a 'turn-on' probe for different DNA topologies was explored.

First, emission titrations were conducted to determine the affinity of DAOTA-M2 to single-stranded (ss) DNA (ss17), dsDNA (CT-DNA and ds17) and G-quadruplex DNA containing two, three or four guanine tetrads (that is, TBA, myc2345 and PDGF-A, respectively). All binding isotherms, calculated association constants and errors are shown in Supplementary Fig. 7 (as well as absorption titrations that were used to determine compound-DNA stoichiometries). These studies show that DAOTA-M2 binds with reasonable affinity $\left(\log K_{\mathrm{a}}\right.$ between 5.7 and 6.1) to all the DNA structures under study.

Moreover, while fluorescence enhancement in the presence of G-quadruplex structures is greater than those of other DNA models (G-quadruplex $=3.3-4.9$; ssDNA/dsDNA $=2.0-2.8$; initial quantum yield 0.032), these differences by steady-state intensity alone would be insufficient for cellular imaging of DNA topologies. This is owing to possible differences in uptake/ intracellular localization altering the effective concentration of the probe and, in turn, the intensity observed. On the other hand, fluorescence lifetimes are concentration independent, and therefore fluorescence lifetime measurements with DAOTA-M2 have the potential for high-contrast measurements to distinguish between different nucleic acid topologies. To do this, TCSPCFLIM was used to measure the emission lifetime of DAOTA-M2 in the presence of a broad range of DNA (dsDNA or ssDNA, 13 models), RNA (dsRNA or ssRNA, 6 models) and G-quadruplex structures (RNA or DNA based, 6 models, see Methods section for comprehensive list of all models).

Interesting trends in the lifetime measurements for different nucleic acid topologies were observed. A bi-exponential decay was necessary to describe the time-resolved data for DAOTA-M2 in the presence of the different nucleic acid structures under study. This implies that more than one 'species' or conformation of the fluorophore exists in these samples. We note that these traces were measured in the presence of at least a twofold excess of nucleic acid compared with the end point of steady-state emission titrations. Thus, the concentration of free compound should be negligible. Furthermore, while the goodness of fit $\left(\chi_{\mathrm{r}}^{2}\right)$ is between 0.8 and 1.3 in all cases, it was anticipated that there would be some correlation of the lifetime and amplitude for each component to achieve the best overall fit. Therefore, for each nucleic acid topology, two-dimensional plots of $\tau_{1}$ versus $\alpha_{1}$ and $\tau_{2}$ versus $\alpha_{2}$ were created (Fig. 3a and Supplementary Fig. 8).

Of the two lifetime components, $\tau_{1} / \alpha_{1}$ offers no contrast between different nucleic acid structures (Fig. 3a). This short and similar lifetime component $\left(\tau_{1}=1-7 \mathrm{~ns}\right)$ indicates that DAOTAM2 resides in an environment independent of the nucleic acid topology. Conversely, the longer $\tau_{2}$ offers a broad spectrum of lifetimes (6-16 ns), progressing from shorter lifetimes for dsDNA and ssDNA to significantly longer lifetimes for RNA and G-quadruplexes. Importantly, when $\alpha_{2}$ is also considered, DNA, RNA and G-quadruplex models can be clearly resolved despite partial overlap of their $\tau_{2}$ values.

To ensure that our observations are independent of the fitting model, all data were analysed using the phasor approach ${ }^{29}$. This involves plotting the real versus imaginary components of a Fourier transform of the decay for each pixel. The centroids of the resultant phasor transform clouds are shown in Fig. 3b. All points lie inside the universal circle (red line) indicating that a multiexponential model is required to analyse the original decay data. Moreover, the separation of DNA, RNA and G-quadruplex signals is comparable to that of the $\alpha_{2}$ versus $\tau_{2}$ plots (Fig. 3a). This clear separation supports our previous assertion that $\mathrm{ss} / \mathrm{ds}$ DNA, RNA and G-quadruplexes can be distinguished by the lifetime of bound DAOTA-M2 and the observed correlation is fitting model independent.

In a cellular context, more dynamic mixtures of nucleic acids should be expected as opposed to regions of only DNA, RNA or G-quadruplex models. Thus, the ability of DAOTA-M2 to detect G-quadruplexes (myc2345 was used as an example) in the presence of dsDNA (CT-DNA) was determined by titrating duplex DNA into a solution of G-quadruplex DNA containing DAOTA-M2 (Fig. 3c). Gradual shifts to shorter $\tau_{2} / \alpha_{2}$ values were observed on increasing CT-DNA concentration as DAOTA-M2 relocated from a G-quadruplex to duplex environment.

The ability of a non-emissive G-quadruplex ligand to displace DAOTA-M2 from G-quadruplexes was also explored. On the addition of increasing amounts of pyridostatin (a well-established G-quadruplex binder ${ }^{17,30}$ ) to a mixture of G-quadruplex DNA, duplex DNA and DAOTA-M2, progressive shifts of $\tau_{2} / \alpha_{2}$ to lower values were observed. This is indicative of DAOTA-M2 being displaced from G-quadruplex DNA by a more selective binder (pyridostatin), and binding to duplex DNA instead (Fig. 3d).

Live-cell imaging with DAOTA-M2. The observed difference in fluorescence lifetimes between nucleic acid models suggested that DAOTA-M2 could be used as an optical probe to study the interactions between a small molecule and G-quadruplexes in live cells. To explore this, cytotoxicity of DAOTA-M2 was first established in the osteosarcoma cell line U2OS (Supplementary Fig. 9). Encouragingly, DAOTA-M2 did not display significant cytotoxicity with an $\mathrm{IC}_{50} \geq 100 \mu \mathrm{M}$ over $24 \mathrm{~h}$ (in comparison with TOTA with an $\mathrm{IC}_{50}=12.7 \pm 2.1 \mu \mathrm{M}$ over $24 \mathrm{~h}$ ). Thus, using confocal microscopy, cellular uptake was investigated using a wide range of DAOTA-M2 incubation times (4-24h) and nontoxic concentrations $(5-20 \mu \mathrm{M})$ in the U2OS cell line.

Confocal microscopy showed clear nuclear staining within $4 \mathrm{~h}$, which was maintained up to $24 \mathrm{~h}$ post treatment (Fig. 4). DNA binding was confirmed by co-localization with Hoechst 33342 (a dsDNA groove binder; Fig. 4b) and displacement of DAOTAM2 by DRAQ-5 (another dsDNA binder; Fig. 4f). Cytoplasmic staining showed co-regional localization with mitochondrial stain Rh123 (ref. 31), and negligible overlap with LysoTracker Green DND-26. Furthermore, it should be noted that intensity-based images displayed enhanced nuclear localization with increasing time and concentration of DAOTA-M2 treatment. Under these experimental conditions, no photobleaching was observed and cell viability was not compromised; SYTOX Green, a cell impermeable dye, did not generate strong nuclear staining (Fig. 4e).

To explore whether the compound binds to G-quadruplexes in live cells, FLIM was carried out. Fluorescence decay traces were 

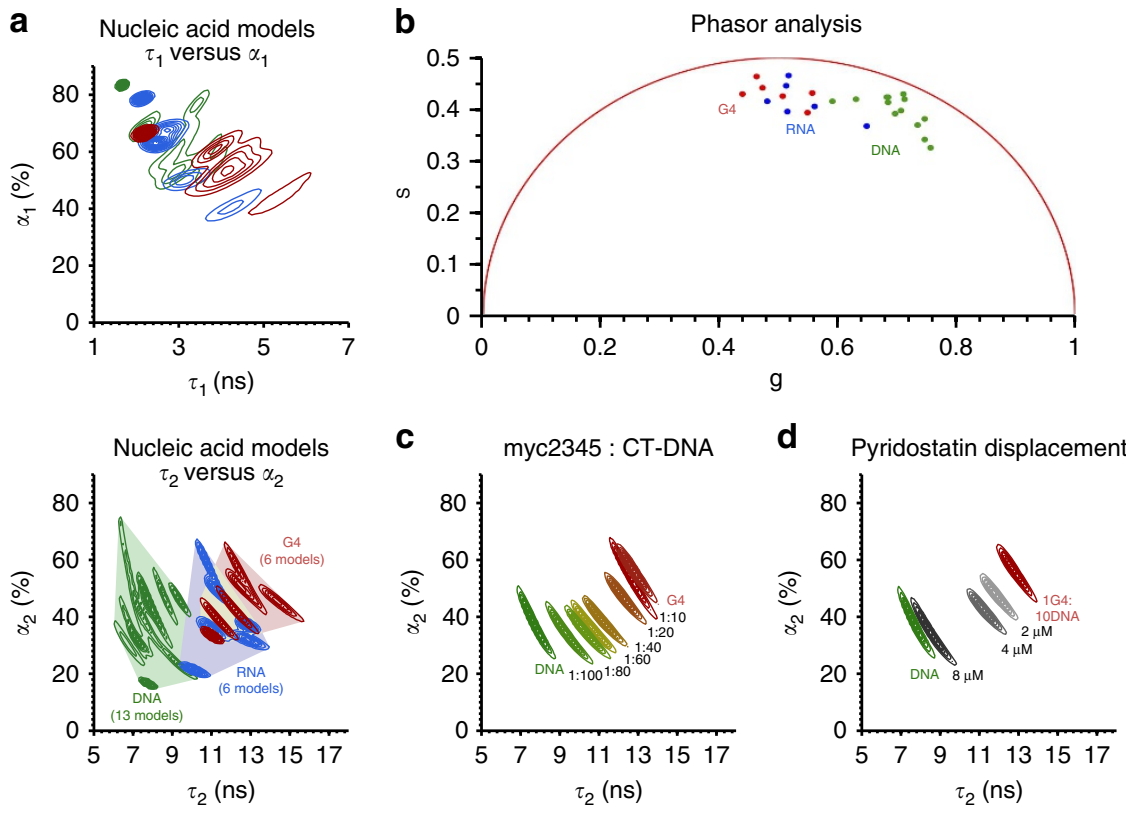

Figure 3 | Fluorescence lifetimes of DAOTA-M2 in the presence of different nucleic acid models in solution as determined by TCSPC-FLIM data

analysis. (a) Contour maps of nucleic acid models for fluorescence lifetime and the corresponding amplitude for each pixel of the FLIM image (512 $\times 512$ ). The difference between each contour level is $5 \%$ of the maximum bin frequency for cumulative G-quadruplexes (red), DNA (green) or RNA (blue) models. The minimum contour contains $95 \%$ of the data for each model based on the maximum bin frequency. For the $\tau_{2}$ versus $\alpha_{2}$ contour map boundaries are also defined for each group of nucleic acid models. (b) The phasor transform centroid for the FLIM image of each individual nucleic acid model, and is colour coded for G-quadruplexes (red), DNA (green) and RNA (blue) models. (c) The $\tau_{2}$ versus $\alpha_{2}$ contour maps for mixtures of G-quadruplex (myc2345) and DNA (CT-DNA). (d) $\tau_{2}$ versus $\alpha_{2}$ contour maps for displacement of DAOTA-M2 from G-quadruplex (myc2345) with increasing concentration of G-quadruplex selective ligand pyridostatin. For all intensity decay traces, fits, residuals, $\chi_{r}^{2}$ distributions and individual nucleic acid model contour plots, see Supplementary Fig. 8.

collected in every pixel of the cellular images captured to study potential differences in the probe's lifetime, which in turn provide a measure of the nucleic acid topology to which DAOTA-M2 was bound (Fig. 5).

As with the in vitro studies (Fig. 3), individual decays in FLIM images of live cells could be accurately fitted by a bi-exponential function. Since $\tau_{2}$ versus $\alpha_{2}$ showed the clearest ability to distinguish in vitro between G-quadruplexes and other nucleic acid topologies, 95\% minimum contour boundaries were defined for each group-DNA, RNA and G-quadruplex-and were colour coded green, blue and red, respectively, while overlapping RNA/G-quadruplex points are shown in yellow. Cellular $\alpha_{2}$ versus $\tau_{2}$ data was superimposed on this colour-coded contour plot (Fig. 5a). Cellular pixels within the defined boundaries were then assigned the appropriate colour to generate colour images (Fig. 5b). In general, the range of $\tau_{2} / \alpha_{2}$ from cells falls within the confines of the model systems, and are at the interface between the RNA and G-quadruplex topologies.

Next, U2OS cells were treated with the non-fluorescent G-quadruplex selective ligand pyridostatin. Based on in vitro models (Fig. 3d), shifts to shorter $\tau_{2} / \alpha_{2}$ values would be expected if pyridostatin displaces DAOTA-M2 from G-quadruplexes. Encouragingly, with increasing pyridostatin incubation times, lower $\tau_{2} / \alpha_{2}$ values were observed (Fig. 5) in addition to a decrease in total fluorescence intensity. Furthermore, treatment of cells with non-specific nucleic acid damaging agent cisplatin for $24 \mathrm{~h}$ failed to generate any significant change in the $\tau_{2} / \alpha_{2}$ values of DAOTA-M2 (Supplementary Figs 12 and 13). Even though the concentration of G-quadruplexes in live cells is expected to be low, our method suggests a change in relative abundance of DAOTA-M2-quadruplex interactions on addition of the competitor ligand pyridostatin. However, it should be noted that owing to the reduction in fluorescence intensity, the sensitivity of this method was impaired and longer acquisition times were necessary. Consequently, challenges still remain to apply DAOTA-M2 as a general probe for G-quadruplex displacement assays in live cells.

\section{Discussion}

There is increasing experimental evidence suggesting that G-quadruplexes play essential roles in key biological processes. As a result, there has been a growing demand for tools to study these non-canonical DNA structures in vivo. While antibodies have been successfully used to image G-quadruplexes in fixed cells, live-cell studies are of vital importance in rigorously addressing the dynamic cause and effect of these structures in vivo. Therefore, the development of cell-permeable smallmolecule optical probes for use in real-time live-cell imaging is highly desirable. In this paper, we have shown that the triangulenium core provides a versatile platform for the design of fluorescent probes. Through the incorporation of essential design features of a good G-quadruplex binder, a novel DNA 'turn-on' probe DAOTA-M2 has been developed. A key feature of this probe is that its emissive lifetime changes considerably upon interaction with different nucleic acid topologies. In particular, significantly higher $\tau_{2} / \alpha_{2}$ values were observed upon interaction of DAOTA-M2 with a wide range of G-quadruplexes, compared with dsDNA or ssDNA. We note that there is some overlap of the probe's $\tau_{2} / \alpha_{2}$ values upon its interaction with G-quadruplexes and RNA-although the values for G-quadruplexes are still consistently higher. Although this is not idealand will indeed need to be optimized in the future-the differences are large enough to be detectable. 
a
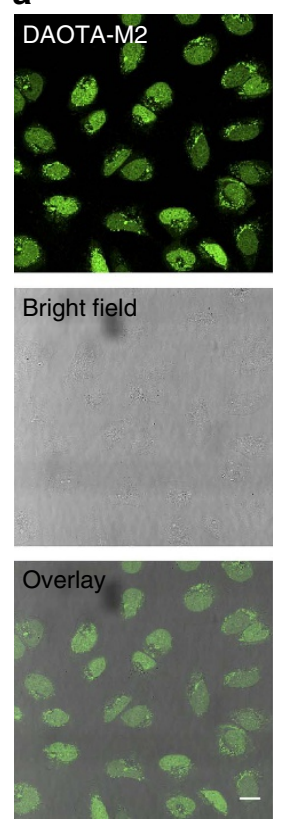

b
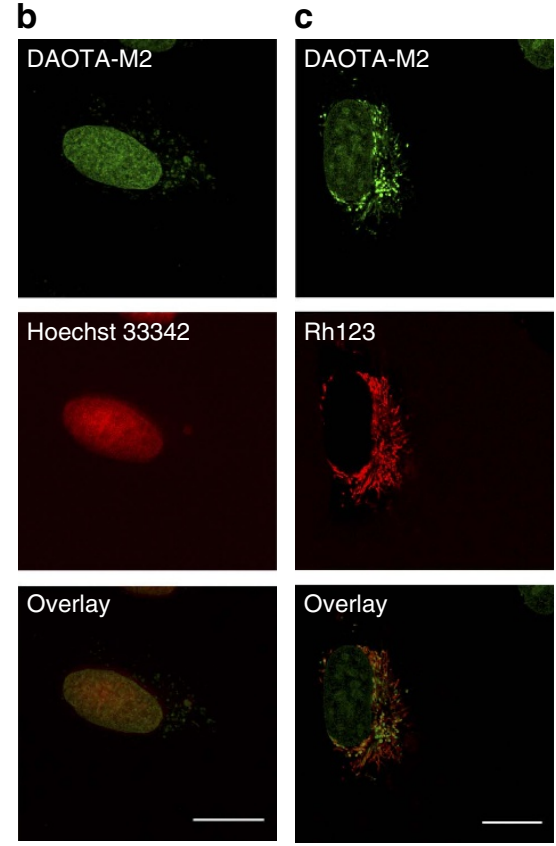

d
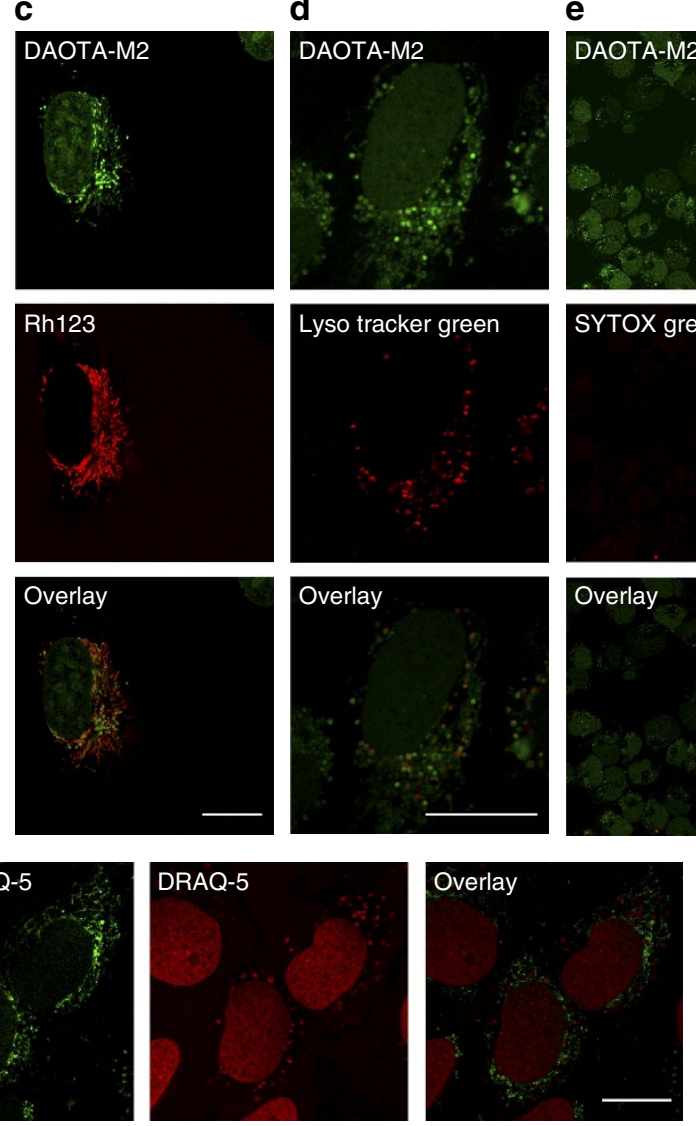

e
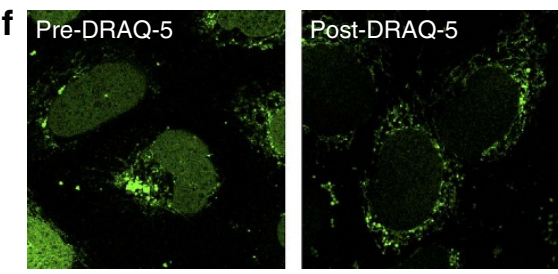
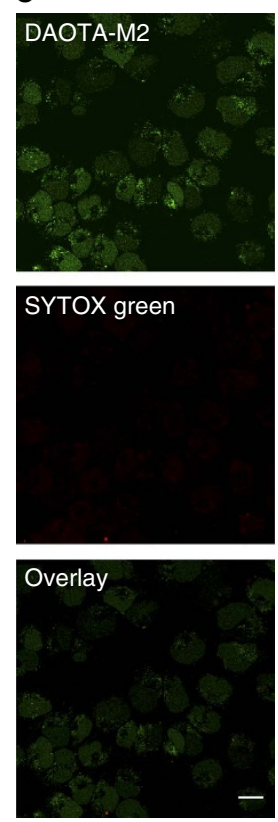

Figure 4 | Confocal microscopy images of U2OS cells incubated with DAOTA-M2. (a) The general staining observed in combination with the transmission bright-field image $(20 \mu \mathrm{M}, 24 \mathrm{~h}$ ). (b -f) Co-localization of DAOTA-M2 (5/20 $\mu \mathrm{M}, 4 / 24 \mathrm{~h}$, green) with (b) Hoechst 33342 ( $5 \mu \mathrm{M}, 30$ min, red), (c) Rh123 ( $5 \mu \mathrm{M}, 3 \mathrm{~min}$, red), (d) LysoTracker Green DND-26 (50 nM, 3 min, red), (e) SYTOX Green ( $2 \mu \mathrm{M}, 5 \mathrm{~min}$, red) and (f) DRAQ-5 (5 $\mu$ M, 30 min, red) obtained by sequential acquisition.

While a two-component model accurately describes all our data, the origin of $\tau_{1}$ and $\tau_{2}$ is not clear for each nucleic acid structure. There are two equally plausible explanations for these observations. The first is that the compound resides in two distinct binding pockets with distinct local environments (for example, groove binding and intercalation $/ \pi-\pi$ stacking). The second is that the compound itself has different excited state lifetimes, and resides in one or more highly similar binding pockets that can be adequately described by $\tau_{1}$ and $\tau_{2}$ (for example, two G-tetrads in the same G-quadruplex, intercalation between different base pairs in duplex DNA). The latter interpretation correlates well with the intramolecular PET transfer quenching observed in purely aqueous systems.

The favourable nuclear localization and minimal toxicity of this new compound also enabled us to carry out FLIM studies in live cells. Our FLIM data suggest that DAOTA-M2 does interact with G-quadruplexes in live cells, as evidenced by high $\tau_{2} / \alpha_{2}$ values observed for this dye in the nuclei of live cells. This is supported by preliminary data that demonstrate a real-time decrease in DAOTA-M2 $\tau_{2} / \alpha_{2}$ values upon addition of pyridostatin-a stronger G-quadruplex binder. To confirm that these observations are due to G-quadruplex interactions as opposed to DNA damage subsequently induced by pyridostatin, a control experiment was performed using cisplatin. Even after $24 \mathrm{~h}$ incubation with this non-specific nucleic acid damaging agent, no significant change in the $\tau_{2} / \alpha_{2}$ values of DAOTA-M2 was observed. This indicates that DNA damage is not responsible for the $\tau_{2} / \alpha_{2}$ changes observed upon pyridostatin treatment, and suggests that our methodology could potentially be used to probe the dynamics of small-molecule/G-quadruplexes interactions in live cells.

This work builds on the growing evidence that small molecules can indeed interact with G-quadruplexes in cellulo, and shows that a useful degree of binding is achievable based on current G-quadruplex ligand design paradigms. Our future efforts will concentrate on designing fluorescence lifetime-based probes that are capable of achieving greater signal differentiation between G-quadruplex- and RNA-binding sites.

\section{Methods}

Full synthetic procedures and characterization of new compounds can be found in Supplementary Methods.

General procedures. Absorption measurements were made on a Perkin-Elmer ultraviolet-visible spectrometer. Emission spectra were obtained on a Varian Cary-Eclipse or Horiba Jobin Yvon Fluorolog fluorescence spectrometer. The oligonucleotides used were purchased RP-cartridge purified from Eurogentec. CT-DNA was obtained from Sigma-Aldrich. pH was measured using a Mettler Toledo $\mathrm{pH}$ meter.

Quantum yield. At least six absorption and emission spectra were recorded of the compound at different concentrations in aerated $10 \mathrm{mM}$ lithium cacodylate buffer ( $\mathrm{pH} 7.3$ ) containing $100 \mathrm{mM}$ potassium chloride. The absorbance was below 0.1 at wavelengths above the excitation wavelength $(436 \mathrm{~nm})$ and emission was collected from 500 to $800 \mathrm{~nm}$. [Ru(byp) $)_{3} \mathrm{Cl}_{2}$ ] in aerated Milli-Q water was used as the reference standard $\left(\Phi_{\mathrm{Ru}}=0.028\right.$; ref. 32$)$. A plot of absorbance $(436 \mathrm{~nm})$ versus integrated emission intensity yielded a linear fit to the equation $y=m x+c\left(R^{2}>0.99\right)$. The quantum yield of the compound was determined by $\Phi_{x}=\Phi_{\mathrm{Ru}}\left(m_{x} / m_{\mathrm{Ru}}\right)$. 
a

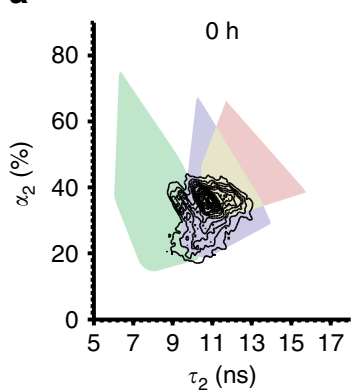

b
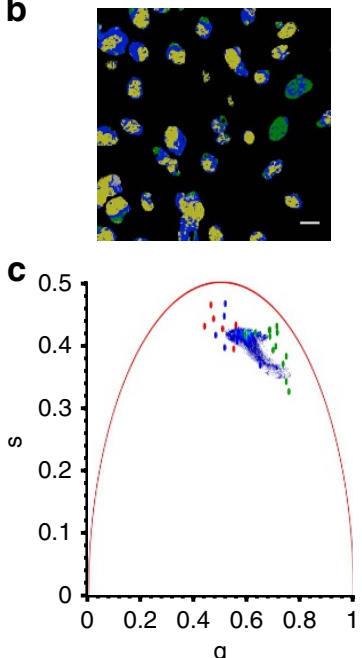

U2OS pyridostatin treatment
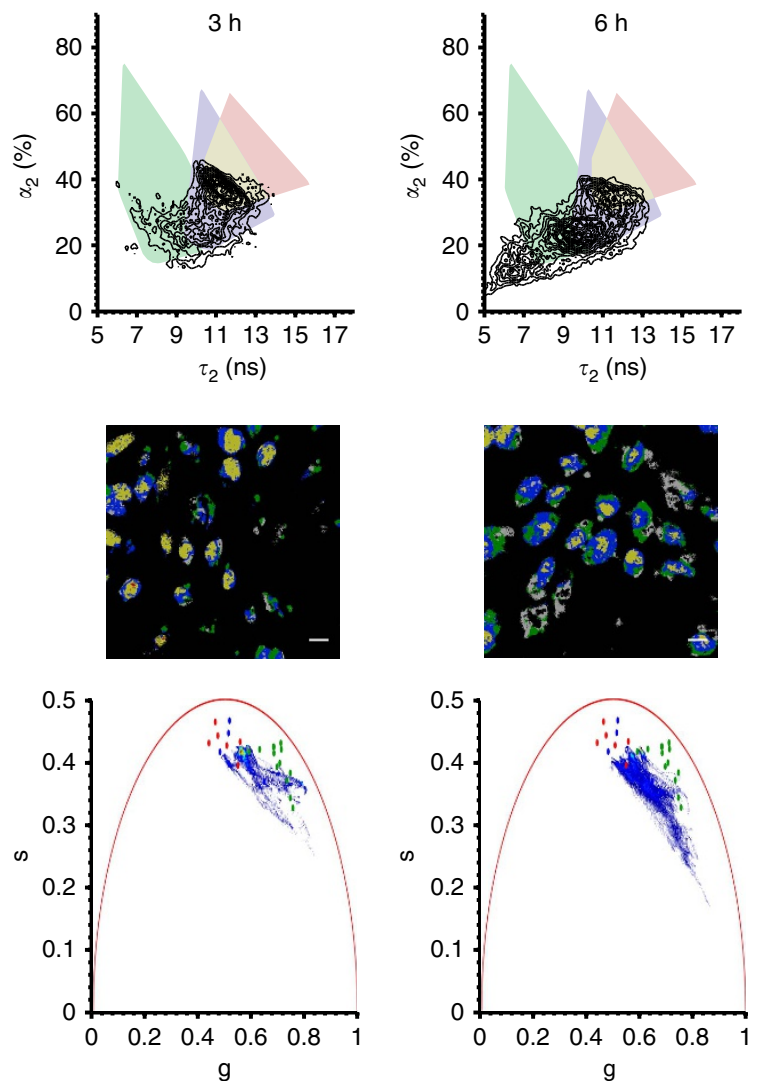

Figure 5 | FLIM visualization of U2OS cells incubated with DAOTA-M2 $(20 \mu \mathrm{M}, 24 \mathrm{~h})$ and subsequently treated with G-quadruplex selective ligand pyridostatin $(\mathbf{1 0} \mu \mathbf{M})$ over time $(\mathbf{0}-\mathbf{6} \mathbf{h})$. (a) Cellular $\tau_{2}$ and $\alpha_{2}$ plotted in the form of a contour map and superimposed on in vitro nucleic acid models boundaries for G-quadruplexes (red), DNA (green), RNA (blue) or overlapping RNA/G-quadruplexes (yellow). The difference between each contour level is $5 \%$ of the maximum bin frequency for the cellular data and the minimum contour contains $95 \%$ of the data relative to the maximum bin frequency. (b) Images are colour coded based on the location of the cellular pixel $\tau_{2}$ and $\alpha_{2}$ with respect to the in vitro models boundaries. Scale bars, $20 \mu \mathrm{m}$. (c) Phasor-transformed cellular fluorescence decays as a heat map of pixels (red-highest frequency, blue-lowest frequency) superimposed on in vitro colour-coded nucleic acid models. See Supplementary Fig. 10 for $\chi_{r}^{2}$, representative decay traces and fits for all data. For data analysis excluding cytoplasmic staining, see Supplementary Fig. 11.

Solvent effects emission spectra. TOTA, ADOTA-M and DAOTA-M2 $(2 \mu \mathrm{M})$ were excited at $404 \mathrm{~nm}$ where absorbance is minimal and emission was monitored from 500 to $750 \mathrm{~nm}$. Fluorescence enhancement or quenching was determined by the integrated fluorescence of the emission spectrum. $\mathrm{pH} 1.0$ and 7.3 measurements were recorded in $0.1 \mathrm{M} \mathrm{HCl}$ and $10 \mathrm{mM}$ lithium cacodylate buffer containing $100 \mathrm{mM} \mathrm{KCl}$, respectively. Measurements in 1,4-dioxane were recorded at $\mathrm{pH} 7.3$ (10 mM lithium cacodylate buffer containing $100 \mathrm{mM} \mathrm{KCl})$. Ionic strength measurements were performed in $10 \mathrm{mM}$ lithium cacodylate buffer ( $\mathrm{pH}$ 7.3) by increasing $\mathrm{KCl}$ concentration from 0 to $220 \mathrm{mM}$.

Time-correlated single photon counting. Time-resolved fluorescence decay traces were obtained using a TCSPC Jobin Yvon IBH data station $(5000 \mathrm{~F}$, HORIBA Scientific Ltd) using a 404-nm excitation source (full width of halfmaximum intensity $(\mathrm{FWHM})=200 \mathrm{ps})$. Samples were prepared as detailed under Solvent effects emission spectra in Methods section. Decays were recorded at the emission wavelengths 520,555 or $575 \mathrm{~nm}( \pm 16 \mathrm{~nm})$ for TOTA, ADOTA-M and DAOTA-M2, respectively, using emission monochromator. Signal intensity was at least 10,000 counts in the peak maximum. Two long-pass filters ( $>490,550$ or $570 \mathrm{~nm}$ long pass) were used in the detection channel to avoid light scattering for fluorescence decays. A neutral density filter was used for the instrument response function (IRF) measurements using a Ludox solution, detecting emission at the excitation wavelength. Traces were fitted by iterative reconvolution to the equation $I(t)=I_{0}\left(\left(1-\alpha_{1}-\alpha_{2}\right) e^{-t / \tau_{1}}+\alpha_{1} e^{-t / \tau_{2}}+\alpha_{2} e^{-t / \tau_{3}}\right)$ where $\alpha_{1}$ and $\alpha_{2}$ are variables and $\alpha$ is normalized to unity. The fractional contribution to the steady-state emission is calculated from the equation $f_{i}=\alpha_{i} \tau_{i} / \sum_{j} \alpha_{j} \tau_{j}$. The average lifetime was calculated using the equation $\bar{\tau}=\sum_{j} f_{j} \tau_{j}$. For mono- or bi-exponential decays, the $\alpha_{1}$ and/or $\alpha_{1}$ terms were set to zero. In the case of solvent polarity, to gain greater accuracy in the lifetimes obtained, a tri-exponential decay model was fitted to decay traces with different 1,4-dioxane percentages using a common $\tau_{1}, \tau_{2}$ and $\tau_{3}$ (global analysis) $^{33}$.
A prompt shift was included in the fitting to take into account differences in the emission wavelength between the IRF and decay as well as the different number of filters used. The goodness of fit was judged by consideration of the deviations from the model via a weighted residuals plot. Least square minimization was performed using the Quasi-Newton algorithm in MatLab (R2013a).

Excited state $\mathbf{p K a} \mathbf{a}^{\star}$ determination. ADOTA-M and DAOTA-M2 $(2 \mu \mathrm{M}, 10 \mathrm{mM}$ sodium phosphate buffer and $0.1 \mathrm{M} \mathrm{KCl}(\mathrm{pH}$ 7.6)) were titrated with citric acid $(3 \mathrm{M})$ from $\mathrm{pH} 7.6$ to 3 (phosphate-citric acid buffer capacity=2.6-7.6; ref. 34). The $\mathrm{pH}$ was read before the emission spectrum was recorded (excitation wavelength $=404 \mathrm{~nm}$ (minimal absorbance), emission wavelength $=500-750 \mathrm{~nm})$. The $\mathrm{pH}$ was then plotted against the numerical derivative $\delta \mathrm{F} / \delta \mathrm{pH}$, where $\mathrm{F}$ is the integrated emission. The minimum was then determined to identify $\mathrm{pKa}{ }^{*}$. Three independent repeats were performed.

List of nucleic acid models. The oligonucleotides used in this study and their corresponding molar extinction coefficients are summarized in Table 2.

DNA annealing. Oligonucleotides were dissolved in buffer containing $100 \mathrm{mM}$ potassium chloride and annealed at $95^{\circ} \mathrm{C}$ for $5 \mathrm{~min}$ before cooling to room temperature overnight on a heat block. Annealing concentrations were $\sim 50-100 \mu \mathrm{M}$ (except for TBA and myc2345, which were $\sim 1 \mathrm{mM}$ ). For PDGF-A, as reported previously, the oligonucleotide was annealed in the same buffer but containing only $25 \mathrm{mM}$ potassium chloride at $15 \mu \mathrm{M}$ concentrations to enable intramolecular folding ${ }^{35}$. For $\mathrm{d}(\mathrm{GC})_{8}$, samples were annealed in buffer containing $5 \mathrm{M}$ sodium chloride to form Z-DNA stock samples ${ }^{36}$. For Z-DNA measurements, this salt concentration was maintained. For normal B-form measurements of $\mathrm{d}(\mathrm{GC})_{8}$, the sodium chloride concentration was reduced to 
Table 2 | Sequences of oligonucleotides used in this study with their corresponding molar extinction coefficients.

\begin{tabular}{|c|c|c|}
\hline Code & Sequence $\left(5^{\prime}-3^{\prime}\right)$ & $\begin{array}{c}\text { Molar extinction } \\
\text { co-efficient } \\
\text { (mol dm } \mathbf{~ m}^{-3} \mathbf{c m}^{-1} \text { ) }\end{array}$ \\
\hline \multicolumn{3}{|l|}{ Quadruplexes } \\
\hline TBA & GGTTGGTGTGGTTGG & 143,300 \\
\hline myc2345 & TGAGGGTGGGGAGGGTGGGGAA & 229,900 \\
\hline PDGF-A & GGAGGCGGGGGGGGGGGGGCGGGG GCGGGGGCGGGGGAGGGGCGCGGC & 467,400 \\
\hline \multicolumn{3}{|l|}{$d s D N A / s s D N A$} \\
\hline ds17 & Equimolar CCAGTTCGTAGTAACCC and GGGTTACTACGAACTGG & 160,900 and 167,400 \\
\hline ATds17 & Equimolar CTATTGCATACTAATTC and GAATTAGTATGCAATAG & 161,000 and 181,500 \\
\hline ss17 & CCAGTTCGTAGTAACCC & 160,900 \\
\hline ATss17a & CTATTGCATACTAATTC & 161,000 \\
\hline dsGA Match & Equimolar TCGTTCACTC and GAGTGAACGA & 85,800 and 109,400 \\
\hline $\mathrm{d}(\mathrm{AT})_{8}$ & ATATATATATATATAT & 177,500 \\
\hline $\mathrm{d}(\mathrm{GC})_{8}$ & GCGCGCGCGCGCGCGC & 134,500 \\
\hline Z-DNA & GCGCGCGCGCGCGCGC & 134,500 \\
\hline CT-DNA & - & 13,200 \\
\hline \multicolumn{3}{|l|}{ dsRNA/ssRNA } \\
\hline GCds17 RNA & Equimolar GGGUUACUACGAACUGG and CCAGUUCGUAGUAACCC & 164,900 and 155,700 \\
\hline GCds17 Hybrid & Equimolar CCAGUUCGUAGUAACCC and GGGTTACTACGAACTGG & 155,700 and 167,400 \\
\hline ATds17 Hybrid & Equimolar CUAUUGCAUACUAAUUC and GAATTAGTATGCAATAG & 169,200 and 181,500 \\
\hline ATss17a RNA & CUAUUGCAUACUAAUUC & 169,200 \\
\hline GCss17a RNA & CCAGUUCGUAGUAACCC & 164,900 \\
\hline tRNA & - & 8,250 \\
\hline
\end{tabular}

$250 \mathrm{mM}$. CT-DNA and transfer RNA (tRNA) was dissolved in buffer containing $100 \mathrm{mM}$ potassium chloride and their concentration was checked using the molar extinction coefficients 13,200 (base pair) and 8,250 (base) $\mathrm{mol} \mathrm{dm}^{-3} \mathrm{~cm}^{-1}$, respectively. Double- and single-stranded nucleic acid model concentrations were converted to base and base pair concentration by multiplying the number of base/base pairs in the sequence.

Absorption and emission titrations. Compound concentration was held constant (20 and $2 \mu \mathrm{M}$ for absorption and emission measurements, respectively) in $10 \mathrm{mM}$ lithium cacodylate buffer ( $\mathrm{pH}$ 7.3) containing $100 \mathrm{mM}$ potassium chloride. Concentrated DNA was then titrated to the compound solution until changes in the absorbance/emission became noticeably indifferent. Fold enhancement of emission was determined by the fluorescence at the end of the titration divided by the initial fluorescence of the compound-only spectrum. Samples were excited at $465 \mathrm{~nm}$, where upon titration of DNA, absorbance changes were negligible $(<0.005)$ as determined by ultraviolet-visible spectroscopic titrations. Emission spectra were recorded from 500 to $800 \mathrm{~nm}$. Three independent repeats were performed. PDGF-A absorption titrations could not be performed due to the low concentration annealing conditions required for intramolecular G-quadruplex formation. Emission titrations were performed by the addition of PDGF-A $(15 \mu \mathrm{M})$ containing DAOTA-M2 $(2 \mu \mathrm{M})$ to a compound-only solution. DAOTA-M2 was added to the PDGF-A DNA to correct for dilution of DAOTA-M2 upon DNA titration. Titration curves were fitted using 1:1 binding model using the absorbance or emission values at $554-504 \mathrm{~nm}$ and $584-634 \mathrm{~nm}$ using a modified form of the MatLab (R2013a) script reported previously ${ }^{37}$. The trust-region-reflective minimization algorithm was used. Binding constants are only reported for emission titrations since the ratio of the initial compound concentration to the calculated absorbance dissociation constants was $\sim 100$ and therefore more error-prone. Instead, the sudden change in gradient of the absorption binding curves was used to determine the stoichiometry of binding (mole ratio method) $)^{38}$. This was a ratio of two compounds per five base pairs (CT-DNA and ds17), one to five bases for ss17, one-to-one G-quadruplex (TBA) and two compounds to one G-quadruplex (myc2345 and PDGF-A). Association constants were then determined relative to the DNA binding motif as defined by the stoichiometry. For example, in the case of ss 17 , the binding constant is reported relative to a binding of one compound to a motif of five bases as opposed to one base. This is based on the assumption that there is no co-operativity in binding and enables all data to be modelled by a oneto-one compound to DNA binding motif stoichiometry ${ }^{39}$.
Fluorescence lifetime nucleic acid models. The oligonucleotides used in this study are detailed under List of Nucleic Acid Models in Methods section. The concentration of DAOTA-M2 relative to nucleic acid was chosen based on DNA emission titrations to ensure minimal unbound compound (DAOTA-M2 $=2 \mu \mathrm{M}$, double-stranded models $=40 \mu \mathrm{M}(\mathrm{bp})$, single-stranded models $=60 \mu \mathrm{M}$ (base), G-quadruplex models $=4 \mu \mathrm{M}$ (strand)). The exceptions were tRNA, GCss17a RNA and $\mathrm{d}(\mathrm{A})_{17}$ where a larger excess of nucleic acid was used $(120 \mu \mathrm{M}$, base) as well as dsGA Mismatch $(80 \mu \mathrm{M}$, base pair). The buffer system was $10 \mathrm{mM}$ lithium cacodylate buffer ( $\mathrm{pH}$ 7.3) containing $100 \mathrm{mM}$ potassium chloride with the exception of Z-DNA and $\mathrm{d}(\mathrm{GC})_{8}$ for which salt concentration was $5 \mathrm{M}$ and $250 \mathrm{mM}$ sodium chloride, respectively.

Cell culture. Bone osteosarcoma U2OS cells (obtained from London Research Institute, Cancer Research UK) were grown in low glucose phenol red-free Dulbecco's modified Eagle medium containing $10 \%$ fetal bovine serum at $37^{\circ} \mathrm{C}$ with $10 \% \mathrm{CO}_{2}$ in humidified air. Cells were seeded on chambered coverglass (ca. $2 \times 10^{4}, 200 \mu \mathrm{l}, 0.8 \mathrm{~cm}^{2}$ ) for 6-24h before the media was replaced with fresh media containing DAOTA-M2 for the specified period of time and concentration $(5-20 \mu \mathrm{M}, 4-24 \mathrm{~h}, 200 \mu \mathrm{l})$. Before imaging, the cells were washed with PBS and the incubation medium was replaced with fresh growth media. For pyridostatin treatment, cells were incubated with DAOTA-M2 for $24 \mathrm{~h}$ before being washed with PBS and grown in media containing pyridostatin $(10 \mu \mathrm{M}, 200 \mu \mathrm{l})$ for the specified times. For cisplatin treatment, cells were co-incubated with DAOTA-M2 $(20 \mu \mathrm{M})$ and cisplatin $(12.5$ and $25 \mu \mathrm{M}, 200 \mu \mathrm{l})$ for $24 \mathrm{~h}$ in medium containing HEPES $(25 \mathrm{mM})$. Cells were then washed with PBS and fresh media were added before imaging. For co-localization experiments, cells were washed with PBS and then incubated with Rh123 (5 $\mu \mathrm{M}, 3 \mathrm{~min})$, Hoechst 33342 (5 $\mu \mathrm{M}, 30 \mathrm{~min})$, DRAQ-5 $(5 \mu \mathrm{M}, 5 \mathrm{~min})$ or LysoTracker Green DND-26 $(50 \mathrm{nM}, 3 \mathrm{~min})$ in PBS $(200 \mu \mathrm{l})$. Cells were then washed with PBS and fresh media were added before imaging. In the case of SYTOX Green $(2 \mu \mathrm{M}, 5 \mathrm{~min}, 200 \mu \mathrm{l}$ PBS), cells were not washed after the addition of the dye.

Cytoxicity assay. Cells were seeded at a density of $5 \times 10^{3}$ per well of a 96-well plate $(50 \mu \mathrm{l})$. After $24 \mathrm{~h}$, compounds were added at the appropriate concentration in triplicate (total volume $100 \mu \mathrm{l}$ ). After a further $24 \mathrm{~h}, 20 \mu \mathrm{l}$ of the MTS Assay reagent was added according to the Promega MTS Assay protocol ${ }^{40}$. Absorbance at $490 \mathrm{~nm}$ (cisplatin, ADOTA-M and DAOTA-M2) or 510 nm (TOTA) was recorded 2-4 h 
after the addition of the reagent. In the case of ADOTA-M and DAOTA-M2, cell treatments were corrected for compound absorbance by subtracting the compoundonly control run in parallel. Absolute $\mathrm{IC}_{50}$ was determined from the equation $\mathrm{IC}_{50}=\mathrm{IC}_{100}+\mathrm{IC}_{0} / 2$, where $\mathrm{IC}_{0}$ is the absorbance of only media and $\mathrm{IC}_{100}$ is the absorbance of DMSO-only-treated cells. Three independent repeats were performed.

Confocal microscopy. Cell treatment conditions can be found under Cell culture in Methods section. Confocal imaging of DAOTA-M2 was performed using a confocal laser-scanning microscope (Leica TCS SP5) with a $\times 63$ (numerical aperture (NA) 1.2) HCX PL APO CS water immersion objective lens with correction collar (11506279, Leica Microsystems, Ltd). The samples were excited using internal microscope lasers and emission intensity was recorded at the appropriate emission wavelength. For co-localization experiments, fluorescence images were sequentially acquired. For DRAQ-5 co-localization, DAOTA-M2 was excited at $458 \mathrm{~nm}$ and its emission was recorded from 550 to $600 \mathrm{~nm}$, whereas DRAQ-5 was excited at $633 \mathrm{~nm}$ and its emission was recorded from 750 to $800 \mathrm{~nm}$. For Hoechst 33342 co-localization, DAOTA-M2 was excited at $514 \mathrm{~nm}$ and its emission was recorded from 600 to $700 \mathrm{~nm}$, whereas Hoechst 33342 was excited at $405 \mathrm{~nm}$ and its emission was recorded from 450 to $500 \mathrm{~nm}$. For Rh123, SYTOX Green and Lysotracker Green DND-26 co-localization, DAOTA-M2 was excited at $561 \mathrm{~nm}$ and its emission was recorded from 700 to $759 \mathrm{~nm}$, whereas the dyes were excited at $488 \mathrm{~nm}$ and their emission was recorded from 510 to $530 \mathrm{~nm}$.

Fluorescence lifetime imaging microscopy. Cell treatment conditions can be found under Cell Culture in Methods section. FLIM imaging of DAOTA-M2 was performed using a pulsed diode laser (Hamamatsu, excitation wavelength $=467 \mathrm{~nm}$, repetition rate $=10 \mathrm{MHz}$ ) coupled into an inverted confocal microscope (Leica TCS SP2) with a $\times 63(\mathrm{NA} \mathrm{1.2)} \mathrm{water} \mathrm{or} \times 63$ (NA 1.4) oil objective. The emission (500-750 nm) was collected using a cooled Becker\&Hickl HPM100-40 hybrid detector, and TCSPC was performed by a SPC-150 Becker\&Hickl module. Images of $512 \times 512$ pixel resolution were captured. The IRF was recorded at $467 \mathrm{~nm}$ using fluorescein quenched by a saturated aqueous solution of sodium iodide ${ }^{41}$. DNA models and cellular images were acquired using the same settings, and the acquisition times was ca. $300 \mathrm{~s}$ (models) and $900 \mathrm{~s}$ (live cells). Lifetime data were fitted to a bi-exponential function for each pixel using Tri2 software ${ }^{42}$ (https://www.assembla.com/spaces/ATD_TRI/wiki). To improve the signal-to-noise ratio, a $21 \times 21$ or $7 \times 7$ pixel smoothing $($ bin $=10$ or 3 ) was used to increase signal intensity for nucleic acid models and cellular images, respectively. For cellular images, a lower bin size and longer acquisition time were used to retain greater spatial resolution of fluorescence decays. Appropriate bin sizes were chosen to ensure a peak count of at least 750 for accurate fitting of bi-exponential traces. Data were then exported and the parameters for each pixel correlated using MatLab (R2013a). Two-dimensional contour maps were constructed with $0.1 \mathrm{~ns}$ or $1 \%$ amplitude bins. The total volume of the contour plot was normalized to one for each model per plot. For example in Fig. 3a, the volume under the combined G-quadruplex models was set to one and this was repeated for the combined RNA and combined DNA models. Thus, the spread of data is directly comparable. The difference between each contour level is $5 \%$ of the maximum bin frequency for the data set and the minimum contour contains $95 \%$ of the data relative to the maximum bin frequency. For cellular images, colours were assigned to each pixel based on both the amplitude and lifetime with respect to the in vitro model data for ssDNA/dsDNA (green), RNA (blue) and G-quadruplex (red) models (as well as overlapping G-quadruplex/RNA models, yellow) to generate a $512 \times 512$ image.

Phasor analysis. Phasor analysis was performed on FLIM images using software written in-house in MatLab (MathWorks). Phasor analysis is a Fourier domain technique that involves plotting the real and imaginary components of the Fourier transform of a fluorescence decay ${ }^{29}$ to provide an alternative two-dimensional representation of the data. The real $(g)$ and imaginary $(s)$ components are calculated as:

$$
\begin{aligned}
& g(\omega)=\frac{\int_{0}^{\infty} I(t) \cos (\omega t) \mathrm{d} t}{\int_{0}^{\infty} I(t) \mathrm{d} t} \\
& s(\omega)=\frac{\int_{0}^{\infty} I(t) \sin (\omega t) \mathrm{d} t}{\int_{0}^{\infty} I(t) \mathrm{d} t}
\end{aligned}
$$

Here $t$ is time, $I(t)$ is the measured fluorescence decay profile and $\omega$ is a parameter that was set to $2 \pi \times 16.6 \mathrm{MHz}$ to have the optimal spread of phasor points obtained from decays with different lifetimes. If the data are measured with a frequency domain FLIM technique, $\omega$ has to be equal to the angular frequency of excitation laser. Phasors of mono-exponential decays lie on the 'universal circle' (a semicircle centred at $g=0.5, s=0$ ), whereas multi-exponential decays produce phasors inside the universal circle. For each fluorescence lifetime image, the phasor transform appears as a diffuse cloud indicating the spread of fluorescence lifetimes. To simplify the visualization of results, where appropriate, the weighted centroid of the phasor cloud was calculated using the MatLab 'regionprops'.

\section{References}

1. Paeschke, K., Capra, J. A. \& Zakian, V. A. DNA replication through G-quadruplex motifs is promoted by the Saccharomyces cerevisiae Pif1 DNA helicase. Cell 145, 678-691 (2011).

2. De Cian, A. et al. Targeting telomeres and telomerase. Biochimie 90, 131-155 (2008).

3. Balasubramanian, S., Hurley, L. H. \& Neidle, S. Targeting G-quadruplexes in gene promoters: a novel anticancer strategy? Nat. Rev. Drug Discov. 10, 261-275 (2011).

4. Biffi, G., Tannahill, D., McCafferty, J. \& Balasubramanian, S. Quantitative visualization of DNA G-quadruplex structures in human cells. Nat. Chem. 5, 182-186 (2013).

5. Biff, G., Di Antonio, M., Tannahill, D. \& Balasubramanian, S. Visualization and selective chemical targeting of RNA G-quadruplex structures in the cytoplasm of human cells. Nat. Chem. 6, 75-80 (2014).

6. Henderson, A. et al. Detection of G-quadruplex DNA in mammalian cells. Nucleic Acids Res. 42, 860-869 (2014).

7. Schmiedeberg, L., Skene, P., Deaton, A. \& Bird, A. A temporal threshold for formaldehyde crosslinking and fixation. PLoS ONE 4, e4636 (2009).

8. Schnell, U., Dijk, F., Sjollema, K. A. \& Giepmans, B. N. Immunolabeling artifacts and the need for live-cell imaging. Nat. Methods 9, 152-158 (2012).

9. Vummidi, B. R., Alzeer, J. \& Luedtke, N. W. Fluorescent probes for G-quadruplex structures. ChemBioChem 14, 540-558 (2013).

10. Largy, E., Granzhan, A., Hamon, F., Verga, D. \& Teulade-Fichou, M. P. Visualizing the quadruplex: from fluorescent ligands to light-up probes. Top. Curr. Chem. 330, 111-177 (2013).

11. Tseng, T. Y. et al. Fluorescent probe for visualizing guanine-quadruplex DNA by fluorescence lifetime imaging microscopy. J. Biomed. Opt. 18, 101309 (2013).

12. Gill, M. R., Garcia-Lara, J., Foster, S. J., Smythe, C., Battaglia, G. \& Thomas, J. A. A ruthenium(II) polypyridyl complex for direct imaging of DNA structure in living cells. Nat. Chem. 1, 662-667 (2009).

13. Wilson, T., Williamson, M. P. \& Thomas, J. A. Differentiating quadruplexes: binding preferences of a luminescent dinuclear ruthenium(ii) complex with four-stranded DNA structures. Org. Biomol. Chem. 8, 2617-2621 (2010).

14. Laguerre, A. et al. Visualization of RNA-quadruplexes in live cells. J. Am. Chem Soc. 137, 8521-8525 (2015).

15. Collie, G. W. \& Parkinson, G. N. The application of DNA and RNA G-quadruplexes to therapeutic medicines. Chem. Soc. Rev. 40, 5867-5892 (2011).

16. Siddiqui-Jain, A., Grand, C. L., Bearss, D. J. \& Hurley, L. H. Direct evidence for a G-quadruplex in a promoter region and its targeting with a small molecule to repress c-MYC transcription. Proc. Natl Acad. Sci. USA 99, 11593-11598 (2002).

17. Rodriguez, R. et al. Small-molecule-induced DNA damage identifies alternative DNA structures in human genes. Nat. Chem. Biol. 8, 301-310 (2012).

18. Faldt, A., Krebs, F. C. \& Thorup, N. Synthesis, structure and properties of various molecules based on the 4,8,12-trioxa-4,8,12,12ctetrahydrodibenzo[cd,mn]pyrene system with an evaluation of the effect differing molecular substitution patterns has on the space group symmetry. J. Chem. Soc. Perkin Trans. 2, 2219-2227 (1997).

19. Laursen, B. W., Krebs, F. C., Nielsen, M. F., Bechgaard, K., Christensen, J. B. \& Harrit, N. 2,6,10-Tris(dialkylamino)trioxatriangulenium ions. Synthesis, structure, and properties of exceptionally stable carbenium ions. J. Am. Chem. Soc. 120, 12255-12263 (1998).

20. Laursen, B. W. \& Krebs, F. C. Synthesis, structure, and properties of azatriangulenium salts. Chem. Eur. J. 7, 1773-1783 (2001).

21. Nicolas, C., Bernardinelli, G. \& Lacour, J. On the synthesis and optical properties of sulfur-bridged analogues of triangulenium cations and their precursors. J. Phys. Org. Chem. 23, 1049-1056 (2010).

22. Thyrhaug, E., Sorensen, T. J., Gryczynski, I., Gryczynski, Z. \& Laursen, B. W. Polarization and symmetry of electronic transitions in long fluorescence lifetime triangulenium dyes. J. Phys. Chem. A 117, 2160-2168 (2013)

23. Maliwal, B. P. et al. Long-lived bright red emitting azaoxa-triangulenium fluorophores. PLoS ONE 8 (2013).

24. Reynisson, J. et al. Intercalation of trioxatriangulenium ion in DNA: binding, electron transfer, X-ray crystallography, and electronic structure. J. Am. Chem. Soc. 125, 2072-2083 (2003).

25. Pothukuchy, A. et al. Duplex and quadruplex DNA binding and photocleavage by trioxatriangulenium lone. Biochemistry 44, 2163-2172 (2005).

26. Dileesh, S. \& Gopidas, K. R. Photoinduced electron transfer in azatriangulenium salts. J. Photochem. Photobiol. A 162, 115-120 (2004).

27. Martin, J. C. \& Smith, R. G. Factors influencing the basicities of triarylcarbinols. the synthesis of sesquixanthydrol. J. Am. Chem. Soc. 86, 2252-2256 (1964).

28. De Silva, A. P. \& Rupasinghe, R.A.D.D. A new class of fluorescent $\mathrm{pH}$ indicators based on photoinduced electron-transfer. J. Chem. Soc. Chem. Commun. 1669-1670 (1985).

29. Digman, M. A., Caiolfa, V. R., Zamai, M. \& Gratton, E. The phasor approach to fluorescence lifetime imaging analysis. Biophys. J. 94, L14-L16 (2008). 
30. Rodriguez, R., Muller, S., Yeoman, J. A., Trentesaux, C., Riou, J. F. \& Balasubramanian, S. A novel small molecule that alters shelterin integrity and triggers a DNA-damage response at telomeres. J. Am. Chem. Soc. 130, 15758-15759 (2008)

31. Johnson, L. V., Walsh, M. L. \& Chen, L. B. Localization of mitochondria in living cells with rhodamine-123. Proc. Natl Acad. Sci. USA 77, 990-994 (1980).

32. Nakamaru, K. Synthesis, luminescence quantum yields, and lifetimes of trischelated ruthenium(II) mixed-ligand complexes including 3,3'-dimethyl-2,2'-bipyridyl. Bull. Chem. Soc. Jpn. 55, 2697-2705 (1982).

33. Lakowicz, J. R. in Principles of Fluorescence Spectroscopy 3rd edn (Springer, 2006).

34. Ruzin, S. E. Plant Microtechnique and Microscopy (Oxford University Press, 1999).

35. Qin, Y., Rezler, E. M., Gokhale, V., Sun, D. \& Hurley, L. H. Characterization of the G-quadruplexes in the duplex nuclease hypersensitive element of the PDGF-A promoter and modulation of PDGF-A promoter activity by TMPyP4. Nucleic Acids Res. 35, 7698-7713 (2007).

36. Klump, H. H., Schmid, E. \& Wosgien, M. Energetics of Z-DNA formation in poly-D(a-T), poly-D(G-C), and poly-D(a-C) poly-D(G-T). Nucleic Acids Res. 21, 2343-2348 (1993).

37. Thordarson, P. Determining association constants from titration experiments in supramolecular chemistry. Chem. Soc. Rev. 40, 1305-1323 (2011).

38. Tsukube, H. et al.in Comprehensive Supramolecular Chemistry (Pergamon, 1996).

39. Bisswanger, H. in Enzyme Kinetics (Wiley-VCH, 2008).

40. Zarei, A. \& Markovic, B. Refinement in the Use and Data Analysis of the Promega CellTiter 96 AQueos Non-radiative Cell Proliferation Assay (Promega Incorporation, 2000).

41. Liu, M. W. et al. Instrument response standard in time-resolved fluorescence spectroscopy at visible wavelength: quenched fluorescein sodium. Appl. Spectrosc. 68, 577-583 (2014)

42. Barber, P. R. et al. Multiphoton time-domain fluorescence lifetime imaging microscopy: practical application to protein-protein interactions using global analysis. J. R. Soc. Interface 6, S93-S105 (2009).

\section{Acknowledgements}

The Engineering and Physical Sciences Research Council of the UK is thanked for financial support including a studentship to A.S. and A.V., and fellowships to M.K.K. (grant number EP/I003983/1) and to R.V. (grant number EP/H005285/1). We are also grateful to European Commission for a Marie Curie Fellowship to M.A.I. Dr David Mann is thanked for donating U2OS cells and helpful advice.

\section{Author contributions}

A.S., M.K.K. and R.V. designed the study and co-wrote the paper. A.S. carried out experiments and analysed the data. A.L.M., K.S. and M.A.I. performed microscopy. A.V. provided code for and performed phasor analysis

\section{Additional information}

Supplementary Information accompanies this paper at http://www.nature.com/ naturecommunications

Competing financial interests: The authors declare no competing financial interests.

Reprints and permission information is available online at http://npg.nature.com/ reprintsandpermissions/

How to cite this article: Shivalingam, A. et al. The interactions between a small molecule and G-quadruplexes are visualized by fluorescence lifetime imaging microscopy. Nat Commun. 6:8178 doi: 10.1038/ncomms9178 (2015).

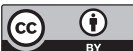

This work is licensed under a Creative Commons Attribution 4.0 International License. The images or other third party material in this article are included in the article's Creative Commons license, unless indicated otherwise in the credit line; if the material is not included under the Creative Commons license, users will need to obtain permission from the license holder to reproduce the material. To view a copy of this license, visit http://creativecommons.org/licenses/by/4.0/ 